\title{
Coupling Biophysical and Socioeconomic Models for Coral Reef Systems in Quintana Roo, Mexican Caribbean
}

\author{
$\underline{\text { Jessica Melbourne-Thomas }}^{1}, \underline{\text { Craig R. Johnson }}^{1}, \underline{\text { Pascal Perez }}^{2}, \underline{\text { Jeremy Eustache }}^{3}, \underline{\text { Elizabeth A. Fulton }}^{4}$, and \\ Deborah Cleland $^{3}$
}

\begin{abstract}
Transdisciplinary approaches that consider both socioeconomic and biophysical processes are central to understanding and managing rapid change in coral reef systems worldwide. To date, there have been limited attempts to couple the two sets of processes in dynamic models for coral reefs, and these attempts are confined to reef systems in developed countries. We present an approach to coupling existing biophysical and socioeconomic models for coral reef systems in the Mexican state of Quintana Roo. The biophysical model is multiscale, using dynamic equations to capture local-scale ecological processes on individual reefs, with reefs connected at regional scales by the ocean transport of larval propagules. The agent-based socioeconomic model simulates changes in tourism, fisheries, and urbanization in the Quintana Roo region. Despite differences in the formulation and currencies of the two models, we were able to successfully modify and integrate them to synchronize and define information flows and feedbacks between them. A preliminary evaluation of the coupled model system indicates that the model gives reasonable predictions for fisheries and ecological variables and can be used to examine scenarios for future socialecological change in Quintana Roo. We provide recommendations for where efforts might usefully be focused in future attempts to integrate models of biophysical and socioeconomic processes, based on the limitations of our coupled system.
\end{abstract}

Key Words: biophysical; coral reefs; coupled models; decision support; socioeconomic; social-ecological systems

\section{INTRODUCTION}

The socioeconomic welfare of millions of people in coastal populations worldwide depends on ecosystem services provided by coral reefs (Moberg and Folke 1999). However, reef ecosystem function, and hence the provision of ecosystem services, is at severe risk because of human activities (Hoegh-Guldberg et al. 2007, Mumby and Steneck 2008). Management of these threats requires novel approaches to decision making (Mumby and Steneck 2008, Sale 2008, Bradbury and Seymour 2009). Although successful management must be based on sound ecological science, the utility of environmental management depends critically on human behavior (Mascia et al. 2003); human behavior affects reef state, and reef state affects human behavior on and around reefs. Hence, there is a need for transdisciplinary efforts to develop decision-support tools for coral reef management
(Bradbury and Seymour 2009). Coral reef research to date has tended to focus on either biophysical dynamics or, to a lesser extent, socioeconomic dynamics. Even when considered separately, biophysical and socioeconomic systems are complex and difficult to understand, and the interactions between the two are necessarily complex (Dizon and Yap 2006). This complexity is exacerbated by differences in language, conceptual frameworks, and approaches to modeling across ecology and socioeconomics (Gurney et al., unpublished manuscript). Nonetheless, recent research on "social-ecological" systems has helped to both capture and improve understanding of some of this complexity and has begun to develop common frameworks for integrating knowledge (Cinner et al. 2009, Ostrom 2009). However, simulation models, which are useful tools for understanding complex systems (Aumann 2007), are relatively underused in social-ecological 
research and integrated environmental management (Gurney et al., unpublished manuscript).

The focus of the work described was to (i) explore how more complete representations of socialecological reef systems could be created by coupling existing "single focus"(biophysical or socioeconomic) models, (ii) provide some evaluation of the coupled product, and (iii) identify key challenges and knowledge gaps for future, more complete, model development. A completely comprehensive representation of a reef system was not the intent of this study, and as such, the extension of the models to incorporate missing feedbacks and the exploration of alternative formulations by means of sensitivity analysis were considered beyond the aims and scope of the work presented here.

\section{Approaches to Modeling Social-Ecological Systems}

Only a limited number of published simulation models have attempted to couple biophysical and socioeconomic dynamics for coral reef systems. Existing models deal mostly with fisheries management (e.g., McClanahan 1995, Gribble 2003, Kramer 2007, Little et al. 2007, Shafer 2007), although Gray et al.'s (2006) model also includes major industries such as shipping, oil and gas production, and salt extraction. The general approach to building these models has been to develop ecological and socioeconomic (or resource exploitation) "modules" that interact as part of a broader social-ecological system. This has the dual advantages of drawing on expertise from different disciplines in the development of separate modules, and fostering transdisciplinary approaches to the definition of interactions between modules. The coupled systems developed by Gribble (2003), Gray et al. (2006), and Little et al. (2007) apply for coastal systems in Australia, whereas Shafer's (2007) model is for reef dynamics in Hawaii. Given that the majority of people who depend on reef systems live in developing countries and not in developed nations like Australia and the United States (Cesar et al. 2003), research to create (social-ecological) decision-support tools for reef managers in developing countries is an important and urgent challenge.

Here, we demonstrate an approach to coupling biophysical and socioeconomic models for coral reefs in the state of Quintana Roo, on the Caribbean coast of Mexico. These models have been developed separately using different platforms and have likewise been calibrated and validated separately (Perez et al. 2009, Melbourne-Thomas et al. 2011b). The biophysical model, CORSET (Coral Reef Scenario Evaluation Tool) has been applied to the Meso-American reef system off the Caribbean coasts of Mexico, Belize, and Honduras, whereas the socioeconomic model (SimReef) describes dynamics specific to Quintana Roo. In the following sections, we discuss management issues facing reefs in Quintana Roo and give brief descriptions of SimReef and CORSET. We then describe our stepwise approach to coupling the models and assess the behavior of the coupled system by comparing model outputs with empirical data and examining changes in coral cover under hypothetical scenarios for increases in the number of tourists visiting the region. We demonstrate that separate modeling tools can be integrated successfully and urge that informed management of coral reefs in the future will employ tools of this kind.

\section{CORAL REEFS IN QUINTANA ROO}

The Mexican state of Quintana Roo occupies the eastern portion of the Yucatan Peninsula (Fig. 1). Fringing reef systems extend along the mainland coast and around the Island of Cozumel, and the state also includes the offshore atoll of Banco Chinchorro(Fig. 1B). These reefs provide important ecosystem services for coastal populations in Quintana Roo; they protect the coast from erosion, moderate the damaging effects of hurricanes, sustain subsistence and commercial fisheries, supply sand for beaches, and generate recreational opportunities (Cinner and Pollnac 2004). Recent census data indicate a population of over one million, and annual tourist visits in the order of eight million (Sistema Estatal de Información Geográfica y Estadistica (SEIGE) 2010: Turismo). Demographic growth over the last 30 years (mainly as migration from neighboring states) has been fuelled by a rapid growth in tourist numbers (Daltabuit et al. 2006). Tourist resorts are highly concentrated in the northern part of the Quintana Roo coast from Cancun to Playa del Carmen on the mainland, and on the island of Cozumel (Fig. 1B); coastal development is rapidly extending southward (Jordán-Dahlgren and Rodríguez-Martínez 2003). The construction of hotels close to the coast has resulted in increased sedimentation, which has negative consequences for reef health (Murray 
Fig. 1. Maps indicating the location and spatial extent of the model region, with the Mexican state of Quintana Roo shaded in dark gray in (B). The location of coral reefs is indicated in red and includes both fringing reefs and the offshore atoll of Banco Chinchorro. The Sian Ka'an Biosphere Reserve, which is the largest protected area in Quintana Roo, is indicated in light gray (between Tulum and Majahual). Dashed lines delineate the four municipalities used in the coupled model.

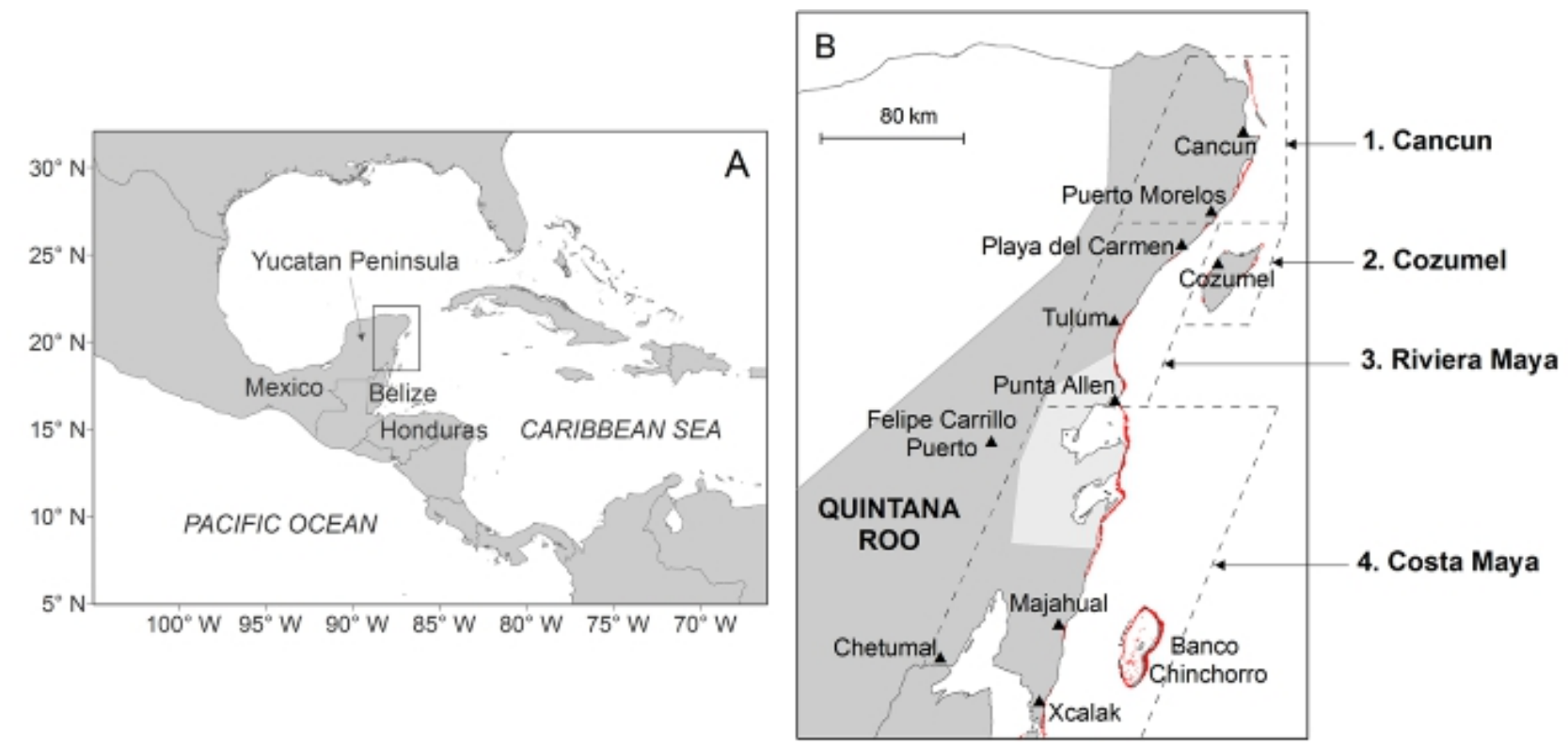

2007). Furthermore, waste water and sewage from resorts and urban areas are generally untreated and are likely to have affected coral reefs in the region (Murray 2007), particularly given that the transport of liquid wastes is facilitated by the highly porous karst geology of the Yucatan Peninsula (Perry et al. 2009).

Coral reefs in Quintana Roo have been subject to intense artisanal fishing since the 1960s (Burke et al. 2004), and overexploitation of fishing resources is considered to be an important environmental impact in the region (Zárate Lomelí et al. 1999). Key fisheries are the Caribbean spiny lobster (Panuliris argus), reef fish, and sharks, and these fisheries are commonly managed by fishing cooperatives that may have concessions to fish within protected areas such as the Puerto Morelos marine protected area (Rodríguez-Martínez 2008) and the Sian Ka'an Biosphere Reserve (AriasGonzález et al. 2004). The queen conch (Strombus gigas) fishery has traditional significance in Quintana Roo, but its deterioration has been such that now it is fished only at Banco Chinchorro and
Cozumel (Arenas Fuentes and Jiménez Badillo 2007). Chronic stressors in the form of overfishing and pollution from coastal development are likely to reduce the resilience of reef systems to disturbances such as hurricanes and coral bleaching events. This effect has been demonstrated for reefs in Belize and Honduras through the use of coral growth records (Carilli et al. 2009). Reduced resilience is of particular concern given projected increases in the frequency of intense Atlantic hurricanes and coral bleaching events in coming decades (Donner 2009, Bender et al. 2010). Localscale, community-oriented programs for sustainable management of reef resources have been documented for Quintana Roo (RodríguezMartínez 2008), but Mexico has no integrated coastal management programs at regional or national scales (Bezaury-Creel 2005).

Previous modeling efforts for the humanenvironment system in Quintana Roo have examined future scenarios for population growth, tourism, and land-use change (Lutz et al. 2000). However, these models are not integrated and have 
not been calibrated or validated, and so are limited to exploratory and heuristic applications. Ecological modeling studies for the region (AriasGonzález 1998, Arias-González et al. 2004) used non-spatial Ecopath platforms to examine differences in trophic structure between protected and non-protected areas, but much of the structure and dynamics of coral reefs is influenced by processes other than trophic ones (e.g., Mumby and Hastings 2008, Melbourne-Thomas et al. 2011a). There is a need for tools that encapsulate the complex social-ecological drivers for the Quintana Roo reef system in a spatially explicit manner and in a way that includes all elements of the broad dynamic of the entire reef system in the region. Such tools would be better placed to assist managers to evaluate alternative options to manage coral reef systems at regional scales.

\section{SIMREEF: A SOCIOECONOMIC MODEL FOR THE QUINTANA ROO COASTAL SYSTEM}

SimReef is an agent-based modeling tool developed for the Quintana Roo coastal system (Perez et al. 2009) that simulates socioeconomic processes that affect reef function. Importantly, local experts and stakeholders participated interactively in the design phase. SimReef is implemented in the SmallTalk language of the Cormas platform (Bousquet et al. 1998), using the open-source, object-oriented program VisualWorks (Cincom Systems, Cincinnati, Ohio, USA) NonCommercial v7.6. The model is structured around four components: (i) fisheries, (ii) tourism, (iii) urbanization, and (iv) reef ecology. Components (i)-(iii) are modeled at the scale of "economic development areas," which correspond approximately with the four municipalities identified in Fig. 1B, whereas reef ecology is modeled at the scale of reef cells (each with an area of approximately $25 \mathrm{~km}^{2}$ ). SimReef uses a gridded base map that identifies the location of resorts, urban areas, and different habitat types (Fig. 2A). The base map is geographically distorted to emphasize areas of ecological and tourism importance. It includes recognizable features of the Quintana Roo region, namely: major cities, Mayan sites, the island of Cozumel, the offshore atoll Banco Chinchorro and the Sian Ka' an Biosphere Reserve. The model has been validated against population growth data for economic development areas of Quintana Roo (Cancun, Cozumel, Riviera Maya, and Costa Maya) for the period 1994-2005 (Perez et al. 2009).
The fisheries component of SimReef models fishing activity for coastal vessels (one to two fishers on board), high sea trawlers and prawn trawlers (five to 10 fishers on board). A simple micro-economic model calculates vessel incomes on a monthly basis using seasonal average catches and approximate market prices for fish, prawns, and lobsters (SEIGE 2010: Pesca). Fishing fleets (comprising 10 vessels) assess the seasonal profitability of their fishing grounds and can select alternative fishing areas based on previous catches. There is no interaction between fishing fleets. Fleets are declared bankrupt when they are unable to meet salary costs over a 1year period.

The tourism component of the model simulates resort development and job creation based on the flow of tourists entering Quintana Roo. Tourist flow is modeled using historical monthly tourism figures (SEIGE 2010; Turismo) and so is effectively a forcing variable. The location of new resorts is based on available land area adjacent to the coast. The tourism component of SimReef resolves different categories of resorts, i.e., one-, three-, and five-star resorts (where the category of new resorts is determined by the number of tourist visits), with higher accommodation and employment capacities as well as greater environmental impacts for higher category resorts (Ávarez Gil et al. 2001). The relationship among environmental impact, resort size, and resort quality is a problematic one, as research suggests that larger, better quality chain hotels tend to have better environmental management systems (Ávarez Gil et al. 2001). However, the overall resource consumption, and therefore, the impact on reefs stemming from activities such as construction and waste-water flows, will still generally be greater from larger hotels of a higher standard (Bohdanowicz and Martinac 2007).

The urbanization component of SimReef assumes a direct link between employment levels in the tourism industry (as determined by the number and category of resorts) and population growth; this relationship is broadly supported by census and employment data for Quintana Roo (SEIGE 2010; Población, Turismo). Urban areas expand adjacent to resort areas and are assumed to have an environmental impact correlated with population size. The environmental impact of resorts and urban areas is represented in the model by means of a simple "environmental impact index" derived from the number of resorts and the extent of urban areas 
Fig. 2. Gridded base maps for (A) SimReef and (B) the coupled model. The SimReef base map is geographically distorted but includes recognizable features of the Quintana Roo region (e.g., Cozumel to the north and Banco Chinchorro to the south). The base map for the coupled model provides a more realistic spatial representation of the region with the location of coral reef cells extracted from reef distribution maps from the University of South Florida's Institute for Marine Remote Sensing Millennium Coral Reef Mapping Project (IMaRS 2004). Asterisks in (B) identify the locations of major ports for fishing vessels, and dashed lines delineate the four municipalities used in the coupled model. Cell dimensions are not explicit in the SimReef base map, but each cell corresponds to an area of approximately $25 \mathrm{~km}^{2}$. The base map for the coupled model uses a grid of $2 \mathrm{~km} \mathrm{x} 2 \mathrm{~km}$ cells.

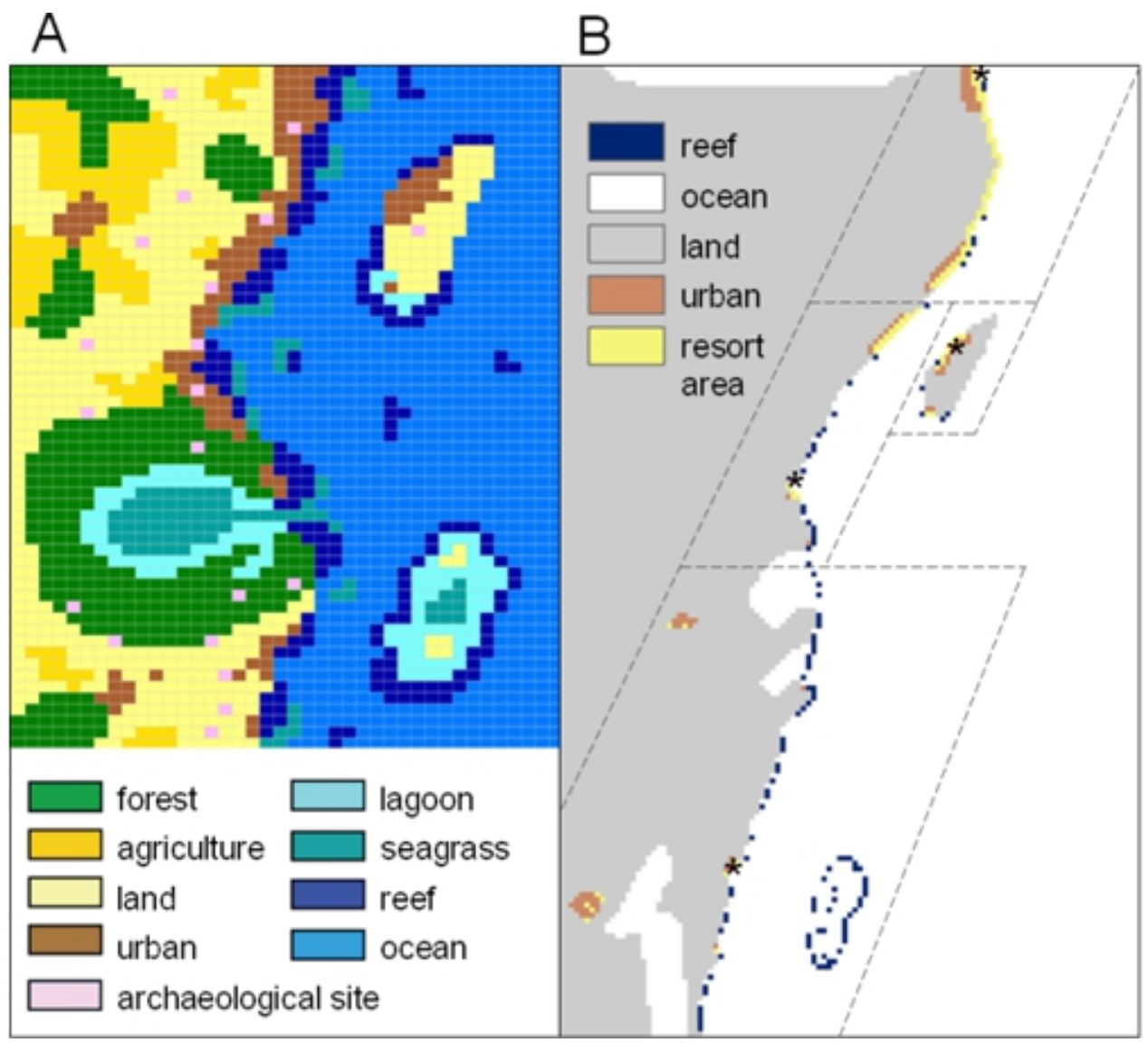

in each economic development area. Finally, the reef ecology component of SimReef uses a highly simplified representation of local-scale ecological dynamics to model changes in coral cover, algal cover, herbivorous fish biomass, and piscivorous fish biomass, after the models of Fung (2009) and Fung et al. (2011). Fishing activity depletes herbivorous and piscivorous fish stocks, and fishermen are presumed to target piscivorous fish preferentially (Pauly et al. 1998). Lobsters and prawns are not included in the reef ecology component; they act as passive stocks that are depleted by fishing activity and have a certain probability of regeneration. SimReef's environmental impact index has no effect on local-scale ecological processes in the stand-alone model; it is simply used as an "indicator" of simulated coastal development.

\section{CORSET: A MULTI-SCALE BIOPHYSICAL MODEL FOR MEXICAN CARIBBEAN REEFS}

CORSET (Coral Reef Scenario Evaluation Tool) is a multi-scale simulation model for a general coral reef system (Melbourne-Thomas et al. 2011b). 
Local-scale ecological dynamics are represented using mean-field equations, and these dynamics are coupled across regional scales by larval dispersal. CORSET uses a "functional group" approach to model interactions between two types of corals (brooding and broadcast spawning species), two types of non-calcareous algae (fleshy and foliose macroalgae and turf algae), the heavily grazed epilithic algal community, which includes nongeniculate coralline algae, herbivorous fish, smallto intermediate-sized piscivorous fish, large piscivorous fish, and sea urchins. Benthic covers of coral and algae and the biomasses of fish and sea urchins are modeled in each reef cell of a gridded base map using a weekly time step. Parameters that describe local-scale ecological processes are selected at random from predefined ranges derived from empirical observations. Parameter values vary between simulation years and between reef cells so that CORSET is stochastic. The model includes representations of "natural" disturbances (hurricanes and disease), broad-scale anthropogenic impacts (coral bleaching events), and direct human impacts (harvesting, nutrification, and sedimentation) as external forcings. CORSET is implemented in the open-source, object-oriented Python Programming Language (Python Software Foundation, Hampton, New Hampshire, USA) version 2.5, and is available online at www.reefscenarios.org. A version of the model for the Meso-American Reef systemincorporating coral reefs off the coasts of Mexico (Quintana Roo), Belize, and Honduras-has been validated for the period 1980-2009 (MelbourneThomas et al. 2011b).

\section{MODEL COUPLING}

Our general approach to coupling SimReef and CORSET was to replace the simplified ecological dynamics in SimReef with the more complex (and realistic) biophysical dynamics described by CORSET. Because the models differ in extent, spatial resolution, and updating time step, the model coupling required modifications to both models, and spatial and temporal synchronization of processes. The crux of the coupling was the definition of information flows and feedbacks between socioeconomic and biophysical "modules." These steps are described in the following sections, together with a brief discussion of external drivers for the coupled system and a preliminary assessment of model behavior.

\section{Modifications to SimReef and CORSET}

To achieve compatibility between the socioeconomic and biophysical models, we made three modifications to SimReef and two modifications to CORSET. The first modification to SimReef was to translate the model into Python (the language in which CORSET is implemented). We chose to translate SimReef, rather than integrating models based on different platforms (as in Villa and Costanza 2000), for two reasons, namely that Python is object-oriented and so is an appropriate language for agent-based models such as SimReef, and because the effort of synchronizing the two models developed on different platforms would have outweighed the effort required to translate SimReef. During the translation process, we removed SimReef's high-seas fleet dynamics, as these do not relate to the coral reef dynamics that are the focus of the coupled system. We also incorporated a limit to the distance travelled by vessels in the coastal fleet of $100 \mathrm{~km}$ per fishing trip. This is a more realistic assumption than allowing vessels to fish over the entire region, given that each vessel must return to its home port and the duration of fishing trips is limited by the amount of fuel that can be carried.

The two modifications made to CORSET were to add population dynamics for spiny lobsters and to modify the larval dispersal scheme. Lobster catches account for approximately two-thirds of the total fisheries profits for Quintana Roo (Instituo Nacional de Estroística Geografia e Informática (INEGI) 2005) and so are clearly an important component of the socioeconomic system for this region (even though, as a functional group, lobsters do not play a prominent role in influencing the broad-scale ecological dynamics). We introduced the following equation for lobster population dynamics into CORSET:

$$
\frac{d L}{d t}=r_{L} L\left(1-\frac{L}{k_{L}}\right)-d_{L} L+l_{L}-f_{L}
$$

Where $d L / d t$ is the rate of change in lobster biomass $L$ (in $\mathrm{kg} / \mathrm{km}^{2}$ ). The parameter $r_{L}$ is the intrinsic growth rate for lobster biomass $=0.335 \mathrm{yr}^{-1}$ and $k_{L}$ $=700 \mathrm{~kg} / \mathrm{km}^{2}$ is the carrying capacity for lobster populations (Food and Agriculture Organization 2003). The growth of lobsters might have been modeled in discrete steps, reflecting the molting process of arthropods (as in Butler et al. 2005) but 
this approach was considered unnecessarily detailed for the purposes of the coupled model for Quintana Roo. Lobster mortality rate $\left(d_{L}=0.3-0.4 \mathrm{yr}^{-1}\right)$ was derived from the 2005 Southeast US Spiny Lobster Stock assessment report (SEDAR 2005). Published estimates are not available for the recruitment rate of 1-yr-old lobster post larvae $\left(l_{L}\right)$, but we derived a theoretical range for this parameter based on published values for mean monthly settlement density ( 0.041 settlers $/ \mathrm{m}^{2}$ for reefs in Florida; Butler et al. 2001) and the weight of yr-old lobster recruits (Chávez 2001). By assuming settlement densities were $50 \%$ of the value reported by Butler et al. (2001) and using their estimate of between 96\%99\% post-settlement mortality, we estimated a theoretical range for $l_{L}=0-6 \times 10^{3} \mathrm{~kg} \mathrm{~km}^{-2} \mathrm{yr}^{-1}$ (the lower bound of this range was extended to zero to account for the possibility of recruitment failure for particular localities). We assumed that lobster recruitment is not dependent on local stocks, i.e., no $L$ multiplier is included for the $l_{L}$ parameter in Eq. 1 . This reflects the very long dispersal period of $P$. argus larvae (an average of 174 days; Goldstein et al. 2008), which means that local-scale recruitment to natal reefs and their near vicinity is likely to be low. Finally, $f_{L}$ is the fishing pressure on lobsters, which is dynamically derived from the socioeconomic module of the coupled model. The modified version of CORSET uses a discrete-time version of Eq. 1, which is solved using the Euler method (with a weekly time step).

The second modification to CORSET was to adjust the larval dispersal scheme to represent larval connectivity between coral reef locations in Quintana Roo, rather than for the whole of the MesoAmerican Reef system (including Belize and Honduras). Larval dispersal is represented in CORSET by larval connectivity matrices that describe transition probabilities for larvae originating in each reef cell reaching (and settling in) every other reef cell in the model domain. These probabilities are derived from sophisticated larval transport simulations that consider both hydrodynamics and larval behavior (Paris et al. 2007). Connectivity matrices are derived separately for corals (broadcast spawning species only), fish, and sea urchins. We modified connectivity matrices to include transition probabilities between reef locations in Quintana Roo only. However, given that reefs in neighboring Belize, and to a lesser extent Honduras, can act as larval sources for Quintana Roo reefs (MelbourneThomas et al. 2011b), we included a fixed larval supply from these "external" sources by assuming uniform values for coral cover, fish biomass, and urchin biomass on Belizean and Honduran reefs (derived as the average of reef state for reef cells in the Quintana Roo model domain at each time step). This approach was used previously in a separate version of CORSET developed for reefs in the Philippines region of the South China Sea (Melbourne-Thomas et al. 2011a) and is adopted here for simplicity. The sensitivity of the model system to alternative assumptions about reef state in external sources is worthy of attention in more detailed evaluations of the behavior of the coupled model beyond those presented here. A connectivity matrix for lobster larvae was not included as information on connectivity patterns for spiny lobster in the Meso-American region is not currently available and these patterns are most likely very different to those for coral, urchin, and fish larvae due to the protracted dispersal period of $P$. argus larvae. Thus, in the coupled model, lobster recruitment varies randomly (i.e., assuming a uniform distribution) within the derived range (0-6 $\mathrm{x} 10^{3} \mathrm{~kg} \mathrm{~km}^{-2} \mathrm{yr}^{-1}$ ) between reef cells and between simulation years.

\section{Synchronizing the Models}

Modified versions of SimReef and CORSET were synchronized by means of a common base map (spatial synchronization) and synchronized time steps (temporal synchronization). The revised base map for the coupled model is spatially realistic and the location of reef cells is properly georeferenced (Fig. 2B). This map comprises a $2 \mathrm{~km} \times 2 \mathrm{~km}$ grid that is divided into four "municipalities," which replace the economic development areas used in SimReef. Temporal synchronization of the models did not require the biophysical and socioeconomic modules to use a common time step; biophysical dynamics in the coupled model are updated every week (as in CORSET) and socioeconomic dynamics use a monthly time step (as in SimReef). Information is passed between the two modules every month, and coupled model output is recorded for each year. Because CORSET is stochastic, the coupled model is also stochastic. In the following section, we discuss the nature of information flows between socioeconomic and biophysical modules of the coupled model. 


\section{Defining Information Flows and Feedbacks}

The primary information flows between the biophysical and socioeconomic modules of the coupled model are summarized in Fig. 3. Tourist resorts and urban areas affect water quality, which is a driver for coral and algal cover. Decreased water quality is modeled using a "pollution index" based on the environmental impact index in SimReef. The pollution index for each reef cell is based on the pollution value for the nearest resort or urban cell, where pollution value $=1.0$ for three-star resorts, 3.0 for five-star resorts, and 5.0 for urban cells. These values scale inversely with the straight-line distance (in number of cells) from the pollution source to each reef cell. Cells with a scaled pollution index of $>0.5$ are assumed to be subject to nutrification and sedimentation impacts. These impacts are detailed in Melbourne-Thomas et al. (2011b) and act to decrease coral growth and recruitment while increasing coral mortality and the growth rate of macroalgae. We note that because quantitative information on nutrient and sediment inputs from coastal development in the region is not currently available, pollution values for resorts and urban cells in SimReef and in the coupled model are unit-less and subjectively selected.

Harvesting of lobsters, herbivorous fish, and piscivorous fish is based on fleet dynamics as in SimReef, with fishing pressure resulting in a direct reduction in fish and lobster biomasses. Fleet dynamics are modeled at the scale of municipalities, with one major port for each municipality (Fig. 2B). The coupled model includes a feedback for fishing activity where fleet dynamics affect fish and lobster stocks, which in turn determine fisher behavior (i.e., the selection of fishing grounds). As in SimReef, a fleet can go bankrupt if its income is insufficient to pay wages. The current version of the coupled model does not include a feedback between the tourism industry and reef state, i.e., an "unhealthy" reef with low coral cover and high algal biomass has no effect on tourist visits. This assumption is reasonable for short-term projections because the state of beaches and, to a lesser extent, the availability of archaeological sites are sufficient to attract tourists even if coral reefs are less appealing for SCUBA divers and snorkelers because of low coral cover (Torres 2002). In the longer term, poor water quality may affect the state of beaches and so result in a decline in the tourism industry (Nichols 1999). However, this longer-term feedback is difficult to model because of a lack of information regarding pollutant levels that result in degraded beaches and the magnitude of declines in tourist numbers precipitated by such degradation.

\section{External Drivers}

External drivers for the coupled model are tourist flow, hydrodynamics, and disturbances to the biophysical system (Fig. 3). As in SimReef, tourist flow is modeled using monthly tourism figures, and in turn drives resort development, population growth, and urbanization. Hydrodynamics is an indirect driver for the biophysical module of the coupled model in that larval connectivity is derived from particle tracking simulations that incorporate complex hydrodynamic features. MelbourneThomas et al. (2011b) demonstrate how larval connectivity drives emergent spatial variation in reef community structure in CORSET, and this variability will have consequences for the behavior and success of fishing fleets in the coupled model. Like CORSET, the coupled model enables simulation of disturbance events, namely hurricanes, coral bleaching, and coral disease events. These disturbances act to reduce coral cover, which has a flow-on effect for fish recruitment, and hence can also influence the success of fishing fleets in the coupled model. The current version of the coupled model does not include the effects of hurricanes on resorts and urban areas (as this was not a focus question for the original version of SimReef). However, given that hurricane damage to coastal areas has been an important socioeconomic driver for Quintana Roo in the past (e.g., the impacts of Hurricane Wilma; SourceMex 2005), future versions of the coupled model will include the effects of hurricanes on resorts and urban areas. We note that the disturbance driver in the coupled model does not include direct damage to coral reef habitats from anchors or from SCUBA divers and snorkelers as these effects are assumed to be localized, i.e., they occur on scales smaller than our $2 \mathrm{~km} \mathrm{x} 2 \mathrm{~km}$ grid. No information is available about the cumulative impacts from direct damage that may manifest at larger spatial scales.

\section{Preliminary Assessment of Model Behavior}

Comparing coupled model outputs with single system results is perhaps the most obvious means of judging the value of expanding model scope by coupling biophysical and socioeconomic components. 
Fig. 3. Coupled model components and drivers. Key information flows between socioeconomic and biophysical modules are indicated by arrows. Tourist flow, hydrodynamics, and disturbance act as external drivers.

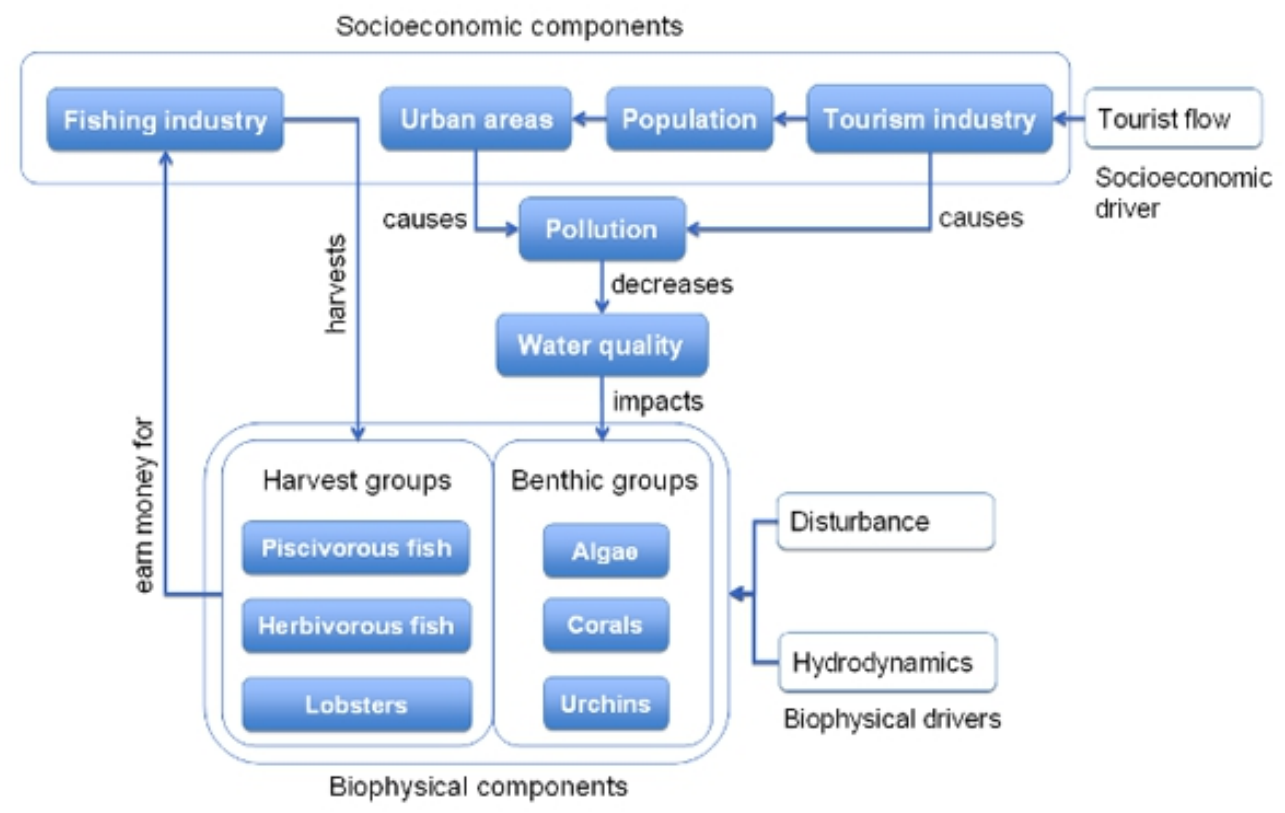

However, such a comparison was not straightforward with the existing independent models as they have been each been tuned to (and validated against) empirical values for the limited period for which data are available. This means that no independent test set remains for checking the coupled model against the single system models. Consequently, we leave that question for future exploration as more data become available. Instead, here we explore the "value-added" features of the coupled system made possible by its ability to examine scenarios that capture feedbacks and responses across an array of variables. We used two approaches to assess the general behavior of the coupled system:

- A comparison of model output with empirical values; and

- An evaluation of model responses under hypothetical scenarios for future changes in the tourism industry in Quintana Roo.

The aim of our first approach was to confirm whether the behavior of the coupled system broadly reflects that of the real system. We compared average simulation end points from Monte Carlo simulations of 10 runs (each covering an 11-year simulation period from 1994-2005) with catch estimates derived from fisheries statistics for Quintana Roo in 2005 (from Mexico's National Institute of Statistics and Geography; INEGI 2005). We also compared modeled values for coral cover, algal cover, herbivorous fish biomass, and piscivorous fish biomass with published values for sites in Quintana Roo from ecological surveys in 2004-2005 (García-Salgado et al. 2006). There was reasonable correspondence between modeled values and empirical ranges for the variables we examined (modeled values were within $20 \%$ of empirical ranges on average, for all variables except algal cover; Table 1). Modeled catches for fish and lobsters were slightly lower than empirical values derived from fishery statistics, however, we note that, at least in the case of fish catches, derived values include catches of non-reef species from high seas fleets (which are not included in the coupled model) and so are likely to be overestimates. Model estimates for algal cover in Quintana Roo were higher than values reported by García-Salgado et al. 
Table 1. Preliminary assessment of the behavior of the coupled model for Quintana Roo. Model output represents average end points from Monte Carlo simulations of 10 runs (each covering an 11-year simulation period from 1994-2005). Socioeconomic variables refer to the sum of fish and lobster catches for the four municipalities (Cancun, Cozumel, Riviera Maya, and Costa Maya), whereas biophysical variables are minimum-maximum ranges across municipalities. Empirical values for fish and lobster catches are estimates based on fisheries statistics for Quintana Roo in 2005 (INEGI 2005). Empirical values for biophysical variables are based on minimum-maximum ranges from ecological surveys in 2004-2005 (García-Salgado et al. 2006).

\begin{tabular}{lcc}
\hline \hline & Model output & Empirical values \\
\hline Socioeconomic variables & & 1500 \\
Fish catch $(t)$ & $740-1390$ & 200 \\
Lobster catch $(t)$ & $150-190$ & \\
Biophysical variables & & $8-40$ \\
Coral cover $(\%)$ & $9-30$ & $0-57$ \\
Algal cover $(\%)$ & $50-80$ & $9-54$ \\
Herbivorous fish biomass $\left(\mathrm{g} / \mathrm{m}^{2}\right)$ & $10-50$ & $0-31$ \\
Piscivorous fish biomass $\left(\mathrm{g} / \mathrm{m}^{2}\right)$ & $0-17$ & \\
\hline
\end{tabular}

(2006) for 2004-2005. However, observations of algal covers across the region in 1999-2000 indicate values between $14 \%$ and $84 \%$, which better accord with model outputs. Our findings under our first approach (comparison of model output with empirical values) demonstrate that the coupled system behaves reasonably well in predicting general reef state and fish and lobster catches over multiple runs with the current parameter set. Further approaches to model validation are described in the Discussion.

Our second approach to evaluating the behavior of the coupled system was based on hypothetical scenarios of increasing tourist numbers in Quintana Roo over a 10 -year period. This is intended as a preliminary demonstration of how the coupled system might be applied in scenario analysis for decision support once it has been more thoroughly evaluated. Census data for Quintana Roo indicate that annual tourist visits increased by a factor of two over the period 1994-2005 (SEIGE 2010: Turismo). The scenarios we examined assumed an increase in annual tourist visits from the number of recorded visits in 2005 to between one and five times the 2005 figure over a 10-year period. We used mean modeled coral cover in the four Quintana Roo municipalities as the response variable for these scenarios. Coral cover is expected to decrease under increased tourist visits as high numbers of visits drive increased hotel building and urban development in the model, both of which act as pollution sources for adjacent coral reefs. Our results indicate that, in Cancun, which is already highly developed, there was no difference in average coral cover after 10 years between the "bestcase" scenario (where there is no further increase in tourist numbers) and the "worst-case" scenario (where tourist numbers increase by a factor of five over the 10-year period; Fig. 4). In contrast, there appears to be a threshold number of tourists that precipitates a pronounced drop in coral cover on reefs in Cozumel and Riviera Maya. Average modeled coral cover was highest on southerly reefs in Costa Maya, but declined steadily in this municipality between a 1.5-factor and 3.5-factor increase in tourist numbers. No additional loss of cover was apparent on reefs in Cozumel, Cancun, 
Fig. 4. Average modeled coral cover in each of the four Quintana Roo municipalities under hypothetical scenarios for increasing tourist visits. These scenarios assume increases in annual tourist visits for the region by a factor of between one (i.e., no increase beyond the number of visits in 2005) and five (i.e., five times 2005 visits) over a 10-year period. Mean coral cover refers to the average cover for each municipality after 10 years. Error bars represent $95 \%$ confidence intervals from the 10 runs of the Monte Carlo simulation.

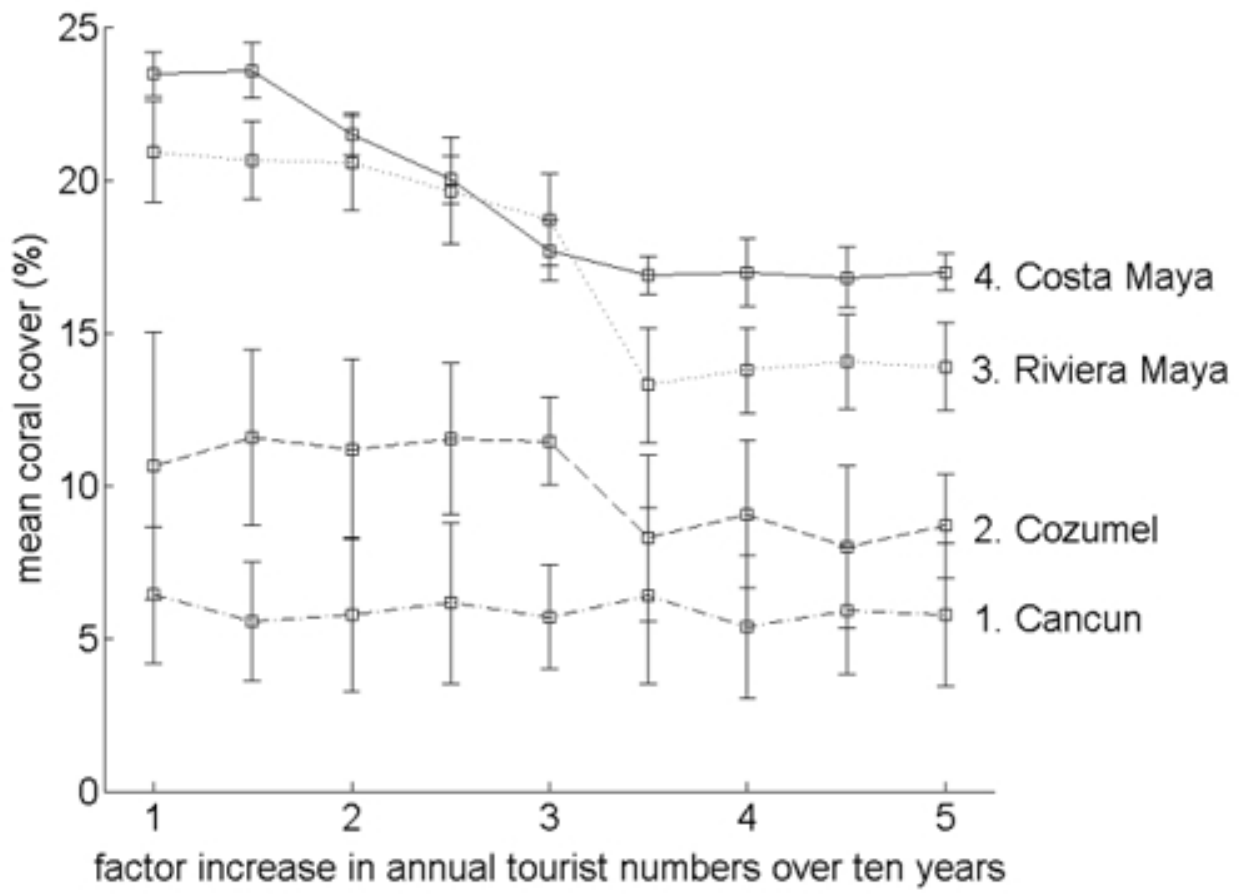

and Costa Maya for more extreme scenarios (>3.5factor increases in tourist numbers).

\section{DISCUSSION}

There is increasing recognition among both scientists and decision makers of the complex, transdisciplinary nature of environmental management problems, and of the interdependencies between biophysical and socioeconomic systems and their dynamics. This complexity, combined with the need to consider social-ecological processes at multiple scales, is a key motivation for integrating different modeling approaches into higher-level simulation models (Villa and Costanza 2000, van Delden et al. 2007; Gurney et al. unpublished manuscript). Here, we demonstrate an approach to coupling biophysical and socioeconomic models for coral reefs in the Mexican state of Quintana Roo. Our coupled system has applications for decision support in coral reef management and the approach itself can inform further attempts to couple dynamic models for human-environment systems. As this modeling work is specific to coral reefs and associated human systems in the Quintana Roo region, we do not feel that it is appropriate to provide generalized prescriptions about coupling complex models.

\section{Coupled Models and Coral Reef Management}

Liu et al. (2007) synthesized results from six case studies from around the world to show that coupled systems exhibit a range of complex behaviors, including nonlinear dynamics, feedback loops, and thresholds, that are not evident in single-discipline studies. However, there have been limited attempts to capture both biophysical and socioeconomic 
dynamics in simulation models for coral reef systems, and documented instances of coupled models are specific to reef systems in developed countries and are not at a whole-of-system level, i.e., they incorporate only some components of the broad structure of reef systems. The coupled system we have presented has the ability to capture socialecological feedbacks that have implications for reef management in the Mexican state of Quintana Roo. Our hypothetical scenarios for increasing tourism development in this region demonstrate the utility of the coupled system in examining ecological responses to socioeconomic forcings, beyond the simplistic assumptions about increases in sedimentation and nutrification presented in Melbourne-Thomas et al. (2011a, b). We note that this example of the advantages of using coupled models is specific to the Quintana Roo coastal system, and readers are referred to Gurney et al. (unpublished manuscript) for a broader discussion of the utility of coupling biophysical and socioeconomic models for understanding and managing human-natural systems.

Predicting the social-ecological impacts of the southward expansion of tourism development in Quintana Roo is a key concern for coastal management in the region (Bezaury et al. 1999), as is the continued pressure from extensive coastal development in the northern municipalities of Cancun and Cozumel. Forcing our coupled model system with increased tourist visits over a 10-year simulation period suggests that tourism-driven coastal development alone is unlikely to result in further declines in coral cover on reefs near Cancun (Fig. 4) where coral cover is already low. However, model results indicate a threshold number of tourists that precipitate significant loss of coral cover on reefs in the three other municipalities (Cozumel, Riviera Maya, and Costa Maya). Tourism development appears to saturate at a certain level so that no further decrease in coral cover is evident in model projections where tourist numbers are greater than or equal to 3.5 times the number of visits in 2005. This pattern is evident for Cancun, an area that is already highly developed, and where reefs are correspondingly already substantially degraded. Reefs in other municipalities are less degraded, and hence there is room for further degradation (up to a point) under increasing pressure from tourism development. Given that the modeled impact of increasing tourist numbers on coral reefs in the Quintana Roo region is mediated by spatial patterns in resort development, and by complex ecological response such as increased algal growth due to nutrification and changes in spatial patterns of larval supply, our scenarios clearly demonstrate the advantages of using a spatially explicit, coupledmodel approach.

We emphasize that our example scenarios are heuristic; other socioeconomic and biophysical factors beyond raw tourist visits are likely to influence trajectories for tourism development and ecological change in Quintana Roo in the future. Given additional threats to reef systems not examined in our hypothetical scenarios, such as increasing frequency or intensity of mass coral bleaching and hurricanes, the regulation of tourism development is likely to be critical in ensuring as resilient a base system as possible. Without such regulation, degradation of the reef ecosystem in the region will make the system even more vulnerable to collapse under cumulative impacts. The coupled model provides a first estimate of the extent to which that development needs to be restrained to maintain reasonable coral cover and functionality of these coastal reef systems.

\section{Dealing with Complexity in Integrated Models}

One particularly challenging issue when creating integrated social-ecological models is dealing with the resolution of representation of processes from all parts of the system. This is exacerbated when differing degrees of information are available on different components of the system. This was the case here where there were quite strong differences in sophistication in the representation of some processes (e.g., pollution moves inversely proportional to the distance from its source, whereas the representation of larval dynamics is quite detailed). Previous empirical work has shown that differential treatment of key processes is preferable to the omission of key processes of feedbacks simply because insufficient information is available for the development of a resolved formulation (Fulton et al. 2003, Gray et al. 2006). In addition, recent work on the design and implementation of agent-based models has shown that thoughtful conjoining of model formulations of different types (e.g., pure individual-based and differential equation-based population representations) is an effective means of achieving computational savings without compromising the veracity of system-level simulations, even when done dynamically within a single agent type (Gray and Wotherspoon, in press). This nicely lays the foundation for the coupling of existing models of different component parts of 
ecosystems, so long as it is done with thought and carefully checked with regard to the realism of the projections and dynamics of the resulting integrated model.

The evaluation of the coupled model described above demonstrates that, in this case, the coupled system can generate realistic and interesting patterns, even though a range of socioeconomic and biophysical components have not yet been incorporated. Although inclusion of the missing components may further improve performance, trade-offs exist in terms of the complexity of coupled biophysical-socioeconomic systems (these are discussed further below). As a result, we think that the system we have presented is appropriately complex in the context our broad preliminary demonstration aims.

\section{Limitations and Recommendations for Integrating Models}

Levins (1966) argues that models of biological populations must trade off generality, precision, and realism because of the complexity of biological systems, and the same is true for models of complex social-ecological systems. The degree of complexity included in a model will depend to a large extent on the question(s) that the model is intended to address and, as highlighted by Fulton et al. (2003), complexity introduced for the sake of completeness achieves nothing if the resulting model is not useful in the context for which it was designed. Our discussion of limitations of our coupled model system for reefs in Quintana Roo relates to the issues of generality and complexity. At the end of this section, we provide recommendations for where efforts might usefully be focused in future attempts to develop integrated models, based on the limitations of our coupled system.

Coupling SimReef and CORSET sacrifices generality; although CORSET is portable between different biogeographic regions as a stand-alone model (Melbourne-Thomas et al. 2011a), the coupled system is specific to Quintana Roo. This is because the existing SimReef tool is region specific; instead of deriving relationships for relatively well understood interactions between organisms (as in CORSET), SimReef was built using a series of assumptions based on much less understood socioeconomic trajectories. Indeed, for tourism development, clear and generic relationships among investment patterns, environments, and resorts have not been described and are unlikely to exist. This is because sociocultural systems (e.g., those in place along the coast of Quintana Roo) exhibit a series of unique socioeconomic characteristics. For example, in Quintana Roo, the central government has a major role in executing the state-wide tourism development plan, the proximity of the United States makes it a highly attractive tourist destination for that large tourist market, and there are strong socioeconomic consequences of drug trafficking in the region (mentioned briefly by Murray (2007), but otherwise poorly documented). Together, these make drawing out generic interaction rules that might be applied elsewhere very difficult. Achieving a portable social-ecological model framework for coral reef systems is a difficult task given the highly contextual nature of many socioeconomic processes. Although the ecological processes that are fundamental to coral reef dynamics can be described by a generic model framework that applies for very different kinds of reef systems around the world (as demonstrated by Melbourne-Thomas et al. (2011a, b)), socioeconomic processes are less amenable to such an approach. Generic socioeconomic models must be based on meta-theories of human decision making (Jager and Janssen 2001). However, many social scientists would argue that such a broad-brushed approach is unlikely to adequately capture the processes driving human-ecological interaction at local or regional scales in particular areas (Cleland et al. 2010).

In addressing complexity for the Quintana Roo reef system, we have attempted to create a "minimumrealistic" model (sensu Punt and Butterworth (1995)) for social-ecological dynamics. However, some potentially important processes have been excluded, which we discuss separately for the socioeconomic and biophysical modules of the coupled system, as well as for the coupling mechanism itself. The socioeconomic module of the coupled system does not yet capture shifting of livelihoods between fishing and tourism industries. This is limiting because livelihood shifting is likely to have occurred in Quintana Roo over the past 30 years, particularly in response to the tourism boom in the north of the state. However, data are not available to confirm whether fishermen left the fishing industry to take up construction and hospitality work in response to this boom. We also note that fuel costs to fishermen are not modeled, even though this factor may influence fisher decisions about how far to travel to fishing grounds. In terms of the tourism industry, our model does not 
capture the negative social consequences of the growth in tourism for communities in Quintana Roo that are summarized by Murray (2007). Future versions of the model could potentially include some index of social welfare. Other socioeconomic components that could, and probably should, be included in future versions of the model are cruise ships, conservation bodies, agriculture and construction industries, drug trafficking, and patterns of investment in tourism development (as addressed in Kandelaars (2000)). Incorporating probability distributions for selected socioeconomic variables would also represent an improvement to future versions of the socioeconomic module.

The biophysical module of the coupled system includes a simple representation of lobster population dynamics. Although this is an improvement on the passive representation of lobster stocks in SimReef (where biomasses have a given probability of regeneration following harvesting), it requires further refinement. In particular, lobster recruitment could be modeled using data from transport simulations for spiny lobster larvae, which are currently being conducted for the Meso-American region (M. J. Butler, personal communication). Other biophysical components that could be explored in future versions of the model include: (i) spawning aggregations for the Nassau grouper (Epinephelus striatus; e.g., at Banco Chinchorro) that are important for the population dynamics of this commercial fish species but that are highly vulnerable to overfishing (Aguilar-Perera and Aguilar-Dávila 1996, Heyman and Requena 2003), and (ii) the role of nursery habitats, particularly mangrove forests, for coral reef fish species (Mumby et al. 2004). Finally, a key limitation of the coupled system in terms of the complexity of the coupling mechanism itself is the absence of feedbacks between reef state and the tourism industry. Such feedbacks are difficult to model in the absence of information about the degree to which "reef health" is important to tourists. As indicated previously, this is not likely to be a problem for short-term projections, but may be an issue in making longer-term predictions of reef futures in the region.

In light of these limitations, we make the following recommendations for where efforts might usefully be focused in future attempts to couple biophysical and socioeconomic dynamics for coral reef systems:
- An important knowledge gap in understanding and modeling socioeconomic dynamics relates to the factors that influence "livelihood switching" in coastal communities, and the ways in which transitions between alternative livelihoods might be incorporated into simulation models. Cultural factors are often important in determining the willingness of stakeholders to change livelihoods (The Nature Conservancy 2008, Cruz-Trinidad et al. 2009) and should be considered in models of socioeconomic dynamics.

- For regions such as Quintana Roo, where the tourism industry is a critical component of the social-ecological system, there is a need for improved understanding of the feedbacks between "ecosystem health" and tourism appeal. In particular, what level of environmental degradation will tourists tolerate in a given region or locality, and how does the behavior of tourists influence degradation? (Acknowledging the fact that there are different kinds of tourists with different interests and tolerance for environmental degradation (Jones et al. 2010))

- Careful consideration should be given to the trade-offs between generality (or portability) and complexity in developing coupled biophysical-socioeconomic systems. Where the development of a portable model framework is an important consideration, methods need to be developed to accommodate contextual differences in socioeconomic processes between regions.

We emphasize that these recommendations are specific to coastal communities and coral reef systems; Gurney et al. (unpublished manuscript) provide more general recommendations for best practices in building interdisciplinary models.

\section{Next Steps}

Our demonstration of model coupling for the socialecological coral reef system in Quintana Roo is the first step in a multi-stage process of model development, testing, and refinement. The next steps in the process will involve: (i) a more detailed assessment of model behavior over the time series 
1994-2005 (results are presented here for a subset of model variables in 2005 only); (ii) model validation using an independent data set, e.g., for the period 2005-2009; and (iii) sensitivity analysis and comparison among different model formulations. Validation is complicated by limited data availability for the region; results from ecological surveys are sporadic in space and time and are not currently available for the period 2005-2008. Previous ecological surveys for reefs in Quintana Roo do not include observations of spiny lobster biomass. Similarly, limited socioeconomic data are available to validate simulated profits for the tourism and fisheries industries. The inclusion of additional socioeconomic and biophysical components discussed above is also limited by data availability. Nevertheless, testing alternative assumptions is an important component of model formulation (Grimm and Railsback 2006) and can also help to identify critical knowledge gaps. Evaluating the consequences of different treatments of similarly complex processes (for example, the well-informed representation of larval transport vs. simple treatment of pollutant dispersal in our coupled model system) is a key challenge in terms of alternative modeling assumptions and is also limited by available knowledge and data. We hope to make a tested version of our coupled model available to support decision making in coral reef management. Our approach can also be used to inform the development of an integrated, portable model framework that captures the social-ecological processes of importance for coral reef systems.

Responses to this article can be read online at: http://www.ecologyandsociety.org/vol16/iss3/art23/ responses/

\section{Acknowledgments:}

This work has been supported by the Modelling and Decision Support (MDS) working group of the Coral Reef Targeted Research and Capacity Building for Management Program (CRTRCBMP). The first author was supported by a joint CSIRO-UTAS PhD Scholarship in Quantitative Marine Science (QMS) and a CSIRO Fellowship in Marine Ecosystem Modelling.

\section{LITERATURE CITED}

Aguilar-Perera, A., and W. Aguilar-Dávila. 1996. A spawning aggregation of Nassau grouper Epinephelus striatus (Pisces: Serranidae) in the Mexican Caribbean. Environmental Biology of Fishes 45:351-361. http://dx.doi.org/10.1007/BF00 $\underline{002527}$

Ávarez Gil, M. J., J. Burgos Jiménez, and J. J. Céspedes Lorente. 2001. An analysis of environmental management, organizational context and performance of Spanish hotels. Omega 29:457471. http://dx.doi.org/10.1016/S0305-0483(01)00033-0

Arenas Fuentes, V., and L. Jiménez Badillo. 2007. Fishing in the Gulf of Mexico: towards greater biomass in exploitation. Pages $468-477$ in $\mathrm{K}$. Withers and M. Nipper, editors. Environmental analysis of the Gulf of Mexico. Harte Research Institute for Gulf of Mexico Studies Special Publication Series No. 1. Texas A\&M University Press, College Station, Texas, USA.

Arias-González, J. E. 1998. Trophic models of protected and unprotected coral reef ecosystems in the south of the Mexican Caribbean. Journal of Fish Biology 53:236-255. http://dx.doi.org/10.1111/j.10 95-8649.1998.tb01030.x

Arias-González, J. E., E. Nuñez-Lara, C. GonzálezSalas, and R. Galzin. 2004. Trophic models for investigation of fishing effect on coral reef ecosystems. Ecological Modelling 172:197-212. http://dx.doi.org/10.1016/j.ecolmodel.2003.09.007

Aumann, C. A. 2007. A methodology for developing simulation models of complex systems. Ecological Modelling 202:385-396. http://dx.doi.o rg/10.1016/j.ecolmodel.2006.11.005

Bender, M. A., T. R. Knutson, R. E. Tuleya, J. J. Sirutis, G. A. Vecchi, S. T. Garner, and I. M. Held. 2010. Modeled impact of anthropogenic warming on the frequency of intense Atlantic hurricanes. Science 327:454-458. http://dx.doi.org/10.1126/sci ence. 1180568

Bezaury-Creel, J. E. 2005. Protected areas and coastal and ocean management in Mexico. Ocean and Coastal Management 48:1016-1046. http://dx. doi.org/10.1016/j.ocecoaman.2005.03.004 
Bezaury, J. C., C. L. Sántos, J. McCann, C. Molina Islas, J. Carranza, P. Rubinoff, G. Townsend, D. Robadue, and L. Hale. 1999. Participatory coastal and marine management in Quintana Roo, Mexico. Pages 9-17 in Proceedings of the International Tropical Marine Ecosystems Management Symposium (ITMEMS). Great Barrier Reef Marine Park Authority, Townsville, Australia.

Bohdanowicz, P., and I. Martinac. 2007. Determinants and benchmarking of resource consumption in hotels-case study of Hilton International and Scandic in Europe. Energy and Buildings 39:82-95. http://dx.doi.org/10.1016/j.enb uild.2006.05.005

Bousquet, F., I. Bakam, H. Proton, and C. Le Page. 1998. Cormas: common-pool resources and multiagent systems. Lecture Notes in Artificial Intelligence 1416:826-838.

Bradbury, R., and R. Seymour. 2009. Coral reef science and the new commons. Coral Reefs 28:831837. http://dx.doi.org/10.1007/s00338-009-0540-6

Burke, L., J. Maidens, M. Spalding, P. Kramer, E. Green, S. Greenhalgh, H. Nobles, and J. Kool. 2004. Reefs at risk in the Caribbean. World Resources Institute, Washington, D.C., USA.

Butler, M. J., T. Dolan, W. Herrnkind, and J. Hunt. 2001. Modelling the effect of spatial variation in postlarval supply and habitat structure on recruitment of Caribbean spiny lobster. Marine and Freshwater Research 52:1243-1252. http://dx.doi.o rg/10.1071/MF01051

Butler, M. J., T. W. Dolan, J. H. Hunt, K. A. Rose, and W. F. Herrnkind. 2005. Recruitment in degraded marine habitats: a spatially explicit, individual-based model for spiny lobster. Ecological Applications 15:902-918. http://dx.doi. org/10.1890/04-1081

Carilli, J. E., R. D. Norris, B. A. Black, S. M. Walsh, and M. McField. 2009. Local stressors reduce coral resilience to bleaching. PLoS ONE 4:e6324. http:// dx.doi.org/10.1371/journal.pone.0006324

Cesar, H., L. Burke, and L. Pet-Soede. 2003. The economics of worldwide coral reef degradation. Cesar Environmental Economics Consulting, WWF-Netherlands, Zeist, The Netherlands.
Chávez, E. A. 2001. Policy design for spiny lobster (Panulirus argus) management at the MesoAmerican Barrier Reef system. Crustaceana 74:1119-1137. http://dx.doi.org/10.1163/15685400 $\underline{152691142}$

Cinner, J. E., T. R. McClanahan, T. M. Daw, N. A. J. Graham, J. Maina, S. K. Wilson, and T. P. Hughes. 2009. Linking social and ecological systems to sustain coral reef fisheries. Current Biology 19:206212. http://dx.doi.org/10.1016/j.cub.2008.11.055

Cinner, J. E., and R. B. Pollnac. 2004. Poverty, perceptions and planning: why socioeconomics matter in the management of Mexican reefs. Ocean and Coastal Management 47:479-493. http://dx.do i.org/10.1016/j.ocecoaman.2004.09.002

Cleland, D., A. Dray, P. Perez, and R. Geronimo. 2010. SimReef and ReefGame: gaming for integrated reef research and management. Pages 124-129 in D. Cleland, J. Melbourne-Thomas, M. King, and G. Sheenan, editors. Building capacity in coral reef science: an anthology of CRTR scholars' research 2010. Coral Reef Targeted Research and Capacity Building for Management Program, The University of Queensland, St. Lucia, Australia.

Cruz-Trinidad, A., R. C. Geronimo, and P. M. Aliño. 2009. Development trajectories and impacts on coral reef use in Lingayen Gulf, Philippines. Ocean and Coastal Management 52:173-180. http://dx.do i.org/10.1016/j.ocecoaman.2008.12.002

Daltabuit, M., L. M. Vasques, H. Cisneros, and G. A. Ruiz. 2006. El turismo en la ecorregion del Sistema Arrecifal Mesoamericano. UNAM-CRIM, Cuernavaca, Mexico. WWF, Washington, D.C., USA.

Dizon, R. T., and H. T. Yap. 2006. Understanding coral reefs as complex systems: degradation and prospects for recovery. Scientia Marina 70:219 226. http://dx.doi.org/10.3989/scimar.2006.70n2219

Donner, S. D. 2009. Coping with commitment: projected thermal stress on coral reefs under different future scenarios. PLOS ONE 4:e5712. htt p://dx.doi.org/10.1371/journal.pone.0005712

Food and Agriculture Organization (FAO). 2003. Report of the second workshop on the management of Caribbean spiny lobsterfisheries in the WECAFC 
area. FAO Fisheries Report No. 715. Food and Agriculture Organization of the United Nations, Rome, Italy.

Fung, T. C. 2009. Local scale models of coral reef ecosystems for scenario testing and decision support. Dissertation, University College of London, London, UK.

Fung, T., R. M. Seymour, and C. R. Johnson. 2011. Alternative stable states and phase shifts in coral reefs under anthropogenic stress. Ecology 92:967982. http://dx.doi.org/10.1890/10-0378.1

Fulton, E. A., A. D. M. Smith, and C. R. Johnson. 2003. Effect of complexity on marine ecosystem models. Marine Ecology Progress Series 253:1-16. http://dx.doi.org/10.3354/meps253001

García-Salgado, M. A., T. L. Camarena, M. G. Vasquez, Gold B., G. G. Galland, Nava M., G. D. Alarcón, and V. M. Ceja. 2006. Baseline of the status of the Mesoamerican barrier reef systems: results of synoptic monitoring from 2004 and 2005. Volume 1. Project for the conservation and sustainable use of the Meso-American barrier reef system (MBRS), Project Coordinating Unit, Belize - Guatemala - Honduras - Mexico, Belize City, Belize.

Goldstein, J. S., H. Matsuda, T. Takenouchi, and M. J. Butler. 2008. The complete development of larval Caribbean spiny lobster Panulirus argus (Latreille, 1804) in culture. Journal of Crustacean Biology 28:306-327. http://dx.doi.org/10.1651/0278-0372(2008) 028[0306:TCDOLC]2.0.CO;2

Gray, R., E. Fulton, R. Little, and R. Scott. 2006. Ecosystem model specification within an agent based framework. NWSJEMS Technical Report No. 16. CSIRO, Hobart, Tasmania, Australia.

Gray, R., and S. Wotherspoon. In press. Increasing model efficiency by dynamically changing model representations. Environmental Modelling and Software.

Gribble, N. A. 2003. GBR-prawn: modelling ecosystem impacts of changes in fisheries management of the commercial prawn (shrimp) trawl fishery in the far northern Great Barrier Reef. Fisheries Research 65:493-506. http://dx.doi.org/1 0.1016/j.fishres.2003.09.035
Grimm, V., and S. F. Railsback. 2006. Agent-based models in ecology: patterns and alternative theories of adaptive behaviour. Pages 139-152 in F. Billari, T. Fent, and A. Prskawetz, editors. Agent-based computational modeling: applications in demography, economics, and environmental sciences. Physica Verlag, Heidelberg, Germany. http://dx.doi.org/10. 1007/3-7908-1721-X 7

Heyman, W., and N. Requena. 2003. Fish spawning aggregation sites in the MBRS region: recommendations for monitoring and management. Reef fish spawning aggregation monitoring protocol for the Mesoamerican reef and the wider Caribbean MBRS Technical Document No. 16. Mesoamerican Barrier Reef Systems Project, Belize City, Belize.

Hoegh-Guldberg, O., P. J. Mumby, A. J. Hooten, R. S. Steneck, P. Greenfield, E. Gomez, C. D. Harvell, P. F. Sale, A. J. Edwards, K. Caldeira, N. Knowlton, C. M. Eakin, R. Iglesias-Prieto, N. Muthiga, R. H. Bradbury, A. Dubi, and M. E. Hatziolos. 2007. Coral reefs under rapid climate change and ocean acidification. Science 318:1737-1742. http://dx.doi. org/10.1126/science.1152509

IMaRS. 2004. Reef_mbr polygon layer: location of coral reefsbenthic structures. University of South Florida Institute for Marine Remote Sensing, Millennium Coral Reef Mapping Project, St. Petersburg, South Florida, USA.

Instituo Nacional de Estroística Geografia e Informática (INEGI). 2005. Anuarios estadísticos del estado de Quintana Roo: 2005, ch 12 Pesca. Instituo Nacional de Estroística Geografia e Informática, Aguascalientes, Mexico.

Jager, W., and M. A. Janssen. 2001. Diffusion processes in demographic transitions: a prospect on using multi agent simulation to explore the role of cognitive strategies and social interactions. SOM (Systems, Organisations and Management) Research Report 01B40. University of Groningen, Groningen, The Netherlands. http://dx.doi.org/10.1007/978-3-7 908-2715-6 4

Jones, T., D. Wood, M. Hughes, T. Pham, D. Pambudi, R. Spurr, L. Dwyer, M. Deery, and L. Fredline. 2010. Tourism destination modelling: building a sustainable planning tool for Australian tourism destinations. CRC for Sustainable Tourism, Gold Coast, Queensland, Australia. 
Jordán-Dahlgren, E., and R. E. RodríguezMartínez. 2003. The Atlantic coral reefs of Mexico. Pages 131-158 in J. Cortés, editor. Latin American coral reefs. Elsevier Press, Amsterdam, The Netherlands. http://dx.doi.org/10.1016/B978-04445 $\underline{1388-5 / 50007-2}$

Kandelaars, P. P. A. A. H. 2000. Integrated dynamic modeling: an application for tourism on the Yucatan Peninsula. Pages 173-203 in W. Lutz, L. Prieto, and W. Sanderson, editors. Population, development, and environment on the Yucatán Peninsula: from ancient Maya to 2030. International Institute for Applied Systems Analysis, Laxenburg, Austria.

Kramer, D. B. 2007. Adaptive harvesting in a multiple-species coral-reef food web. Ecology and Society 13(1): 17. [online] URL: http://www.ecolog yandsociety.org/vol13/iss1/art17/

Levins, R. 1966. The strategy of model building in population biology. American Scientist 54:421431.

Little, L. R., A. E. Punta, B. D. Mapstone, F. Pantus, A. D. M. Smith, C. R. Davies, and A. D. McDonald. 2007. ELFSim-A model for evaluating management options for spatially structured reef fish populations: an illustration of the "arval subsidy"effect. Ecological Modelling 205:381-396. http://dx.doi.o rg/10.1016/j.ecolmodel.2007.03.005

Liu, J., T. Dietz, S. R. Carpenter, M. Alberti, C. Folke, E. Moran, A. N. Pell, P. Deadman, T. Kratz, J. Lubchenco, E. Ostrom, Z. Ouyang, W. Provencher, C. L. Redman, S. H. Schneider, and W. W. Taylor. 2007. Complexity of coupled human and natural systems. Science 317:1513-1516. http://dx. doi.org/10.1126/science. 1144004

Lutz, W., L. Prieto, and W. Sanderson, editors. 2000. Population, development, and environment on the Yucatán Peninsula: from ancient Maya to 2030. International Institute for Applied Systems Analysis, Laxenburg, Austria.

Mascia, M., B., J. P. Brosius, T. Dobson, A., B. Forbes, C., L. Horowitz, M. McKean, A., and N. Turner, J. 2003. Conservation and the social sciences. Conservation Biology 17:649-650. http:// dx.doi.org/10.1046/j.1523-1739.2003.01738.x
McClanahan, T. R. 1995. A coral reef ecosystem fisheries model: impacts of fishing intensity and catch selection on reef structure and processes. Ecological Modelling 80:1-19. http://dx.doi.org/10 $.1016 / 0304-3800(94) 00042-\mathrm{G}$

Melbourne-Thomas, J., C. R. Johnson, P. M. Aliño, R. C. Geronimo, C. L. Villanoy, and G. G. Gurney. 2011a. A multi-scale biophysical model to inform regional management of coral reefs in the western Philippines and South China Sea. Environmental Modelling and Software 26:66-82.

Melbourne-Thomas, J., C. R. Johnson, T. Fung, R. M. Seymour, L. M. Chérubin, J. E. Arias-González, and E. A. Fulton. 2011b. Regional-scale scenario modeling for coral reefs: a decision support tool to inform management of a complex system. Ecological Applications 21:1380-1398. DOI: 10.1890/09-1564.1 http://dx.doi.org/10.1890/09-1564.1

Moberg, F., and C. Folke. 1999. Ecological goods and services of coral reef ecosystems. Ecological Economics 29:215-233. http://dx.doi.org/10.1016/S 0921-8009(99)00009-9

Mumby, P. J., A. J. Edwards, J. Ernesto AriasGonzález, K. C. Lindeman, P. G. Blackwell, A. Gall, M. I. Gorczynska, A. R. Harborne, C. L. Pescod, H. Renken, C. C. C. Wabnitz, and G. Llewellyn. 2004. Mangroves enhance the biomass of coral reef fish communities in the Caribbean. Nature 427:533536.

Mumby, P. J., and A. Hastings. 2008. The impact of ecosystem connectivity on coral reef resilience. Journal of Applied Ecology 45:854-862. http://dx.d oi.org/10.1111/j.1365-2664.2008.01459.x

Mumby, P. J., and R. S. Steneck. 2008. Coral reef management and conservation in light of rapidly evolving ecological paradigms. Trends in Ecology and Evolution 23:555-563. http://dx.doi.org/10.1016/ j.tree.2008.06.011

Murray, G. 2007. Constructing paradise: the impacts of big tourism in the Mexican coastal zone. Coastal Management 35:339-355.

Nichols, K. 1999. Coming to terms with "integrated coastal management": problems of meaning and method in a new arena of resource regulation. The 
Professional Geographer 51:388-399. http://dx.doi. org/10.1111/0033-0124.00174

Ostrom, E. 2009. A general framework for analyzing sustainability of social-ecological systems. Science 325:419-422. http://dx.doi.org/10 $.1126 /$ science. 1172133

Paris, C. B., L. M. Chérubin, and R. K. Cowen. 2007. Surfing, spinning, or diving from reef to reef: effects on population connectivity. Marine Ecology Progress Series 347:285-300. http://dx.doi.org/10. $\underline{3354 / \mathrm{meps} 06985}$

Pauly, D., V. Christensen, J. Dalsgaard, R. Froese, and F. Torres. 1998. Fishing down marine food webs. Science 279:860-863. http://dx.doi.org/10.11 $\underline{\text { 26/science. } 279.5352 .860}$

Perez, P., A. Dray, D. Cleland, and J. E. AriasGonzález. 2009. An agent-based model to address coastal management issues in the Yucatan Peninsula, Mexico. Pages 72-79 in Proceedings of the Eighteenth World IMACS Congress and MODSIM09 International Congress on Modelling and Simulation Modelling and Simulation Society of Australia and New Zealand and International Association for Mathematics and Computers in Simulation, Cairns, Australia.

Perry, E., A. Paytan, B.Pedersen, and G. VelazquezOliman. 2009. Groundwater geochemistry of the Yucatan Peninsula, Mexico: constraints on stratigraphy and hydrogeology. Journal of Hydrology 367:27-40. http://dx.doi.org/10.1016/j.j hydrol.2008.12.026

Punt, A. E., and D. S. Butterworth. 1995. The effects of future consumption by the Cape fur seal on catches and catch rates of the Cape hakes. 4. Modelling the biological interaction between Cape fur seals Arctocephalus pusillus pusillus and the Cape hakes Merluccius capensis and M. paradoxus. South African Journal of Marine Science 16:255285.

Rodríguez-Martínez, R. E. 2008. Community involvement in marine protected areas: the case of Puerto Morelos reef, México. Journal of Environmental Management 88:1151-1160. http:// dx.doi.org/10.1016/j.jenvman.2007.06.008

Sale, P. F. 2008. Management of coral reefs: where we have gone wrong and what we can do about it.
Marine Pollution Bulletin 56:805-809. http://dx.do i.org/10.1016/j.marpolbul.2008.04.009

SEDAR. 2005. Assessment of spiny lobster, Panulirus argus, in the southeastern United States: stock assessment. US Stock Assessement Panel, National Oceanic and Atmospheric Administration, South Atlantic Fishery Management Council, North Charleston, South Carolina, USA.

Sistema Estatal de Información Geográfica y Estadistica (SEIGE). 2010. Anuarios estadísticos del estado de Quintana Roo, Edición 2009. SEIGE. [online] URL: http://seplader.seige.qroo.gob.mx/se igeweb/IndiceAnuario2009.php

Shafer, J. L. 2007. Agent-based simulation of a recreational coral reef fishery: linking ecological and social dynamics. Dissertation, University of Hawaii, Honolulu, Hawaii, USA.

SourceMex. 2005. Hurricane Wilma inflicts severe damage on tourism infrastructure in Quintana Roo state. SourceMex Economic News and Analysis on Mexico, 2 November 2005, Thomson Gale, Farmington Hills, Michigan, USA.

The Nature Conservancy. 2008. Livelihood transitions: towards sustainable fishing communities in the Mesoamerican reef region. The Nature Conservancy and USAID, Mesoamerican Reef Program, Guatemala City, Guatemala.

Torres, R. 2002. Cancun's tourism development from a Fordist spectrum of analysis. Tourist Studies 2:87-116.

van Delden, H., P. Luja, and G. Engelen. 2007. Integration of multi-scale dynamic spatial models of socio-economic and physical processes for river basin management. Environmental Modelling and Software 22:223-238. http://dx.doi.org/10.1016/j.e nvsoft.2005.07.019

Villa, F., and R. Costanza. 2000. Design of multiparadigm integrating modelling tools for ecological research. Environmental Modelling and Software 15:169-177. http://dx.doi.org/10.1016/S1364-8152 (99)00032-8

Zárate Lomelí, D., T. Saavedra Vázquez, J. L. Rojas Galavíz, A. Yáñez-Arancibia, and E. R. Arriaga. 1999. Terms of reference towards an integrated management policy in the coastal zone of the Gulf 
of Mexico and the Caribbean. Ocean and Coastal

Management 42:345-368. http://dx.doi.org/10.1016/ $\underline{\text { S0964-5691(98)00060-X }}$ 